\title{
Spina bifida and birth outcome before and after fortification of flour with iron and folic acid in Oman
}

D. Alasfoor, ${ }^{7}$ M.K. Elsayed ${ }^{7}$ and A.J. Mohammed ${ }^{1}$

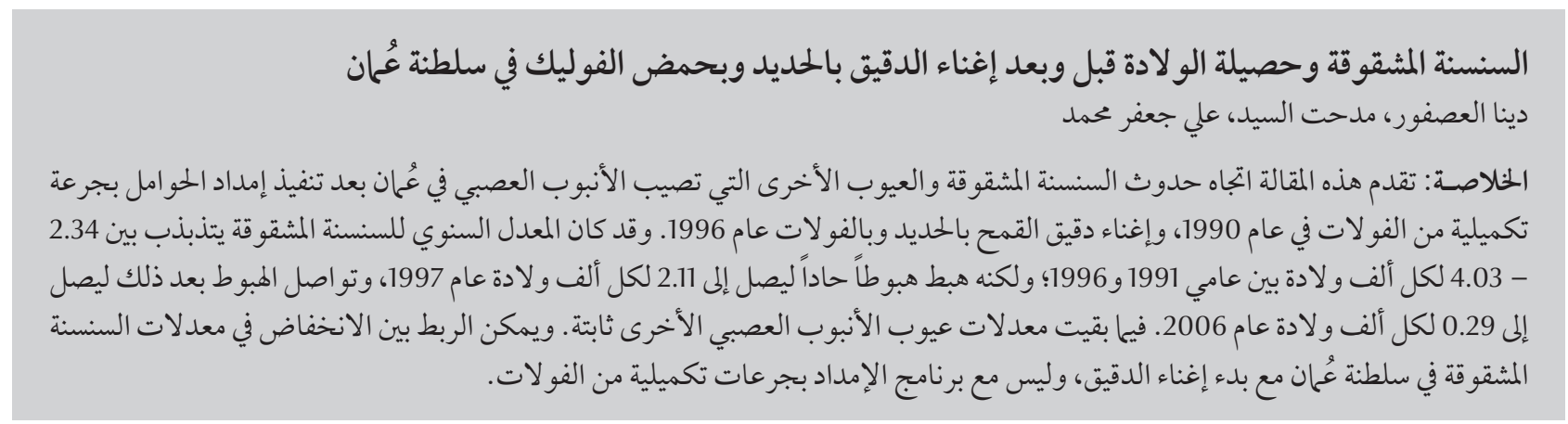

ABSTRACT This paper presents the trend of spina bifida and other neural tube defects in Oman after the nationwide implementation of folate supplementation of pregnant women in 1990 and the fortification of wheat flour with iron and folate in 1996. The annual incidence of spina bifida fluctuated from 2.34 to 4.03 per 1000 deliveries between 1991 and 1996, but fell sharply to 2.11 per 1000 deliveries in 1997, after which the downward trend continued, reaching 0.29 per 1000 deliveries by 2006. The rate of other neural tube defects remained almost constant. The reduction in spina bifida rates in Oman could be linked to the start of flour fortification but not the supplementation programme.

Spina bifida et accouchement avant et après l'instauration de la farine enrichie en fer et en acide folique à Oman

RÉSUMÉ Cet article présente la tendance du spina bifida et d'autres malformations du tube neural à Oman, après la mise en place au niveau national de la supplémentation en acide folique chez les femmes enceintes en 1990, et l'enrichissement de la farine de blé en fer et en acide folique en 1996. Entre 1991 et 1996, le taux annuel de cas de spina bifida oscillait entre 2,34 et 4,03 pour 1000 accouchements. En 1997, il a soudain chuté à 2,11 pour 1000 accouchements et la tendance à la baisse s'est poursuivie pour atteindre 0,29 pour 1000 en 2006. Le taux d'incidence d'autres malformations du tube neural est resté pratiquement constant. La réduction du nombre de cas de spina bifida à Oman pourrait être liée à l'instauration de l'enrichissement de la farine, mais pas au programme de supplémentation. 


\section{Introduction}

Some of the most serious neurological anomalies that develop in the first 2 months of gestation are neural tube defects (NTD), including spina bifida, which is a defective closure of the vertebral column which typically manifests after birth as a visible lesion in the back [1]. The folate status of women of childbearing age and pregnant women has been shown to be an important factor contributing to the occurrence of spina bifida and some other NTD. Dietary diversification, folate supplements and food fortification with folic acid are the 3 most common strategies to improve the folate status of women of childbearing age. Clinical trials show that folate supplementation during pregnancy can contribute to prevention of NTD [2]. Fortification of cereals with folate was associated with a reduction of up to $75 \%$ in NTD in the United States of America (USA) and Canada [3,4].

In Oman, a national supplementation programme was started in 1990 to provide all pregnant women with a daily dose of $200 \mathrm{mg}$ iron and $5 \mathrm{mg}$ folic acid [5]. While the supplementation programme continues, in 1996 the Ministry of Commerce, based on the request of the Ministry of Health, mandated the fortification of white flour with $30 \mathrm{ppm}$ iron as elemental (electrolytic) iron and $5 \mathrm{mg} / \mathrm{kg}$ folic acid [6]. By 2004 the household coverage of fortified flour and products in Oman was 81\% [7].

We aimed to demonstrate the effectiveness of folic acid fortification of flour as a public health strategy in preventing NTD. We estimated per capita consumption of folic acid and measured the trends of NTD rates before and after fortification, as well as spontaneous abortion rates in Oman from 1991 to 2006. This is the first evidence from a developing country of the effectiveness of folic acid fortification on the outcomes of NTD on a population level.

\section{Methods}

\section{Morbidity data}

We used the Ministry of Health Annual statistical reports for the years 1991-2006 to monitor the trends in the rates of spina bifida and other NTD, spontaneous abortions and early neonatal $(<7$ days $)$ and late neonatal (7-28 days) mortality.

Inpatient morbidity data in Oman are based on discharge diagnoses recorded using the International Statistical Classification of Diseases and Related Health Problems (ICD). Hospital data before 1997 were recorded using the basic tabulation list of ICD-9 and so the codes used for the pre-1997 data in this study were the combined codes for spina bifida and hydrocephalus (741) and (742.3). After 1997 hospital data were recorded using ICD-10 codes and the codes used for this study were spina bifida (Q05.9) and other NTD (Q06.9) [8].

The data for inpatient morbidity were collected from all government health facilities. These clinic-based data are representative of the national level as the Omani population enjoys high accessibility to government-provided health services. The rate of hospital deliveries has been consistently above $95 \%$ since 1996 and the majority of deliveries take place in government institutions, as the number of hospital beds in private health facilities constitute less than $3 \%$ of all hospital beds available in the country during the time that the data were recorded [9].

The morbidity and mortality statistics presented here were obtained from the network of hospitals linked to the statistics database of the Ministry of Health of Oman. These were 47 hospitals with 3419 beds in 1990, which increased to 49 hospitals with 4542 beds in 2005 .

\section{Folic acid consumption data}

Household income and expenditure data from Oman [10] were used to estimate the average food consumption for a household for a year (May 1999 to May 2000). We analysed the diet using Food processor for Windows, version 8.4.0, a specialized dietary analysis program [11], and compared the folic acid content of the average diet with and without flour fortification.

\section{Results}

\section{Incidence of congenital anomalies and neural tube defects}

The annual incidence of congenital anomalies and NTD for the years 1991-2006, based on the Omani annual health statistics reports are shown in Figure 1. Table 1 shows the changes in these rates since 1990, when the folate supplementation for pregnant women was started, and since 1996, when flour fortification was begun. There was no clear pattern observed in the incidence of spina bifida between 1991 and 1996, fluctuating from 2.34 to 4.03 per 1000 deliveries, whereas after this period a sharp decline was observed, with the rate of spina bifida falling from 3.06 per 1000 deliveries in 1996 to 2.11 in 1997, a $31 \%$ reduction. The downward trend continued and by 2006 the incidence was 0.29 per 1000 deliveries, an $88 \%$ reduction on the 1996 incidence. The annual incidence of other NTD per 1000 deliveries did not show the same downward trend over the period that they were recorded (1997-2006).

Figure 2 shows that early and late neonatal mortality and abortion rates declined by $16 \%, 39 \%$ and $6 \%$ respectively in 1997 compared with 1996. The decline continued after 1997 to reach $43 \%, 60 \%$ and $30 \%$ for early neonatal rates, late neonatal rates and abortion respectively. The rates of low birth weight remained fairly constant at 8 per 1000 live births.

\section{Consumption of folic acid}

Our estimates showed that without food fortification the average folic acid 


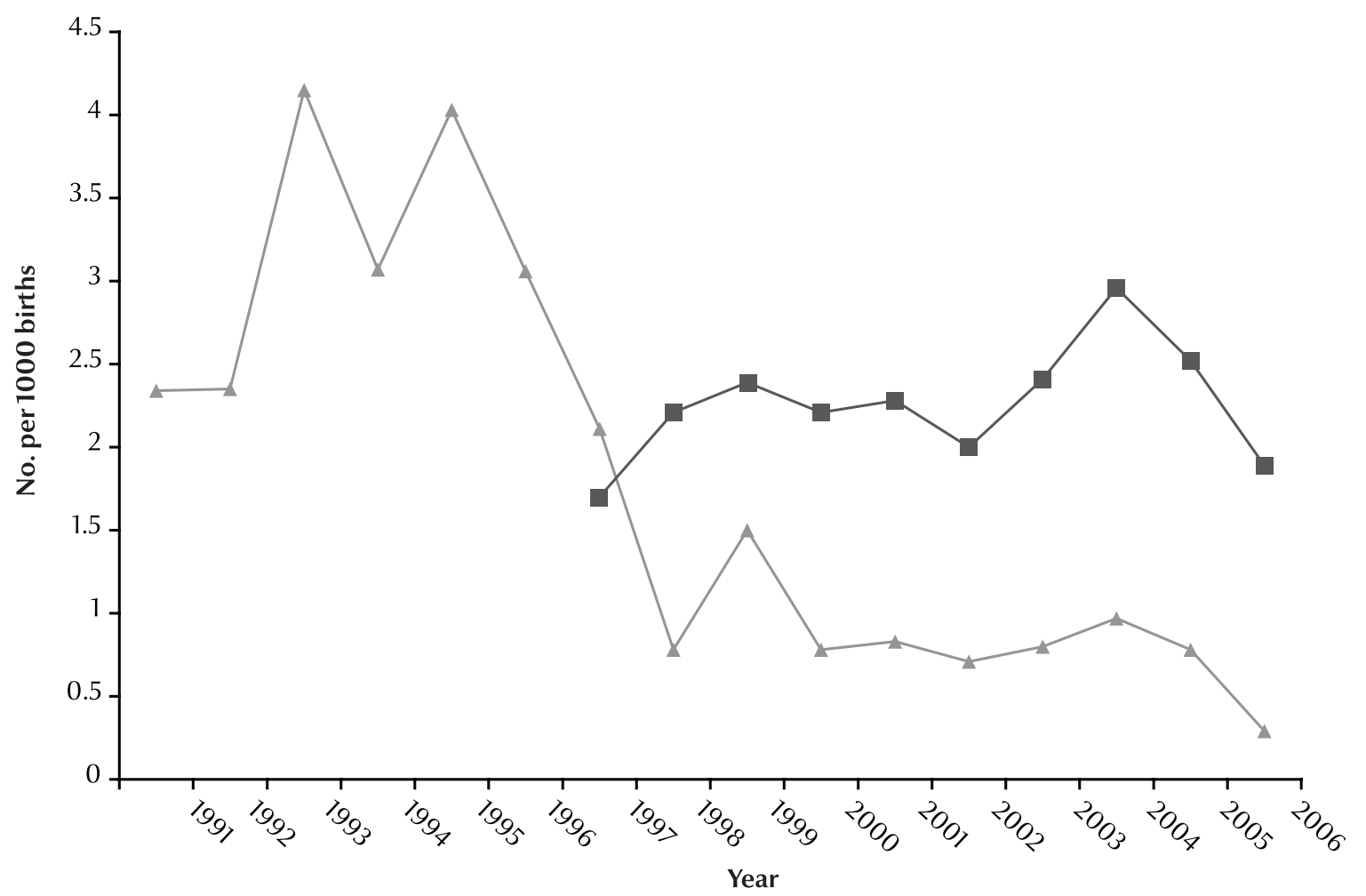

Figure 1 Incidence of spina bifida $(\Delta)$ and other neural tube defects $(\square)$ per 1000 births in Oman, 1991-2006

intake of the Omani population was only $123 \mu \mathrm{g}, 33 \%$ of the per capita requirements, based on average energy requirement levels of $2100 \mathrm{kcal}$ and the estimated average per capita folate folate density goals of $150-200 \mu \mathrm{g}$ per level in the diet would increase to 489 $1000 \mathrm{kcal}[12,13]$. With fortification, $\mu \mathrm{g}$ (122\% of the target) for an energy

\begin{tabular}{|c|c|c|c|c|c|}
\hline \multirow[t]{2}{*}{ Year } & \multicolumn{3}{|c|}{ Spina bifida } & \multicolumn{2}{|c|}{ NTD } \\
\hline & $\begin{array}{l}\text { Rate per } 1000 \\
\text { births }\end{array}$ & $\begin{array}{l}\% \text { change } \\
\text { from } 1990\end{array}$ & $\begin{array}{l}\% \text { change } \\
\text { from } 1996\end{array}$ & $\begin{array}{c}\text { Rate per } \\
1000 \text { births }\end{array}$ & $\begin{array}{l}\% \text { change } \\
\text { from } 1996\end{array}$ \\
\hline 1991 & 2.34 & 0 & - & - & - \\
\hline 1992 & 2.35 & 0 & - & - & - \\
\hline 1993 & 4.15 & +0.77 & - & - & - \\
\hline 1994 & 3.07 & +0.31 & - & - & - \\
\hline 1995 & 4.03 & +0.72 & - & - & - \\
\hline 1996 & 3.06 & +0.31 & - & - & - \\
\hline 1997 & 2.11 & -0.10 & 1 & 1.70 & 1 \\
\hline 1998 & 0.78 & -0.66 & -0.63 & 2.21 & +0.30 \\
\hline 1999 & 1.50 & -0.36 & -0.29 & 2.39 & +0.41 \\
\hline 2000 & 0.78 & -0.66 & -0.63 & 2.21 & +0.30 \\
\hline 2001 & 0.83 & -0.64 & -0.61 & 2.28 & +0.34 \\
\hline 2002 & 0.71 & -0.69 & -0.66 & 2.00 & +0.18 \\
\hline 2003 & 0.80 & -0.66 & -0.62 & 2.41 & +0.42 \\
\hline 2004 & 0.97 & -0.59 & -0.54 & 2.96 & +0.74 \\
\hline 2005 & 0.78 & -0.66 & -0.63 & 2.52 & +0.48 \\
\hline 2006 & 0.29 & -0.88 & -0.86 & 1.89 & +0.11 \\
\hline
\end{tabular}

Adapted from the annual health statistics of the Ministry of Health, Oman. 


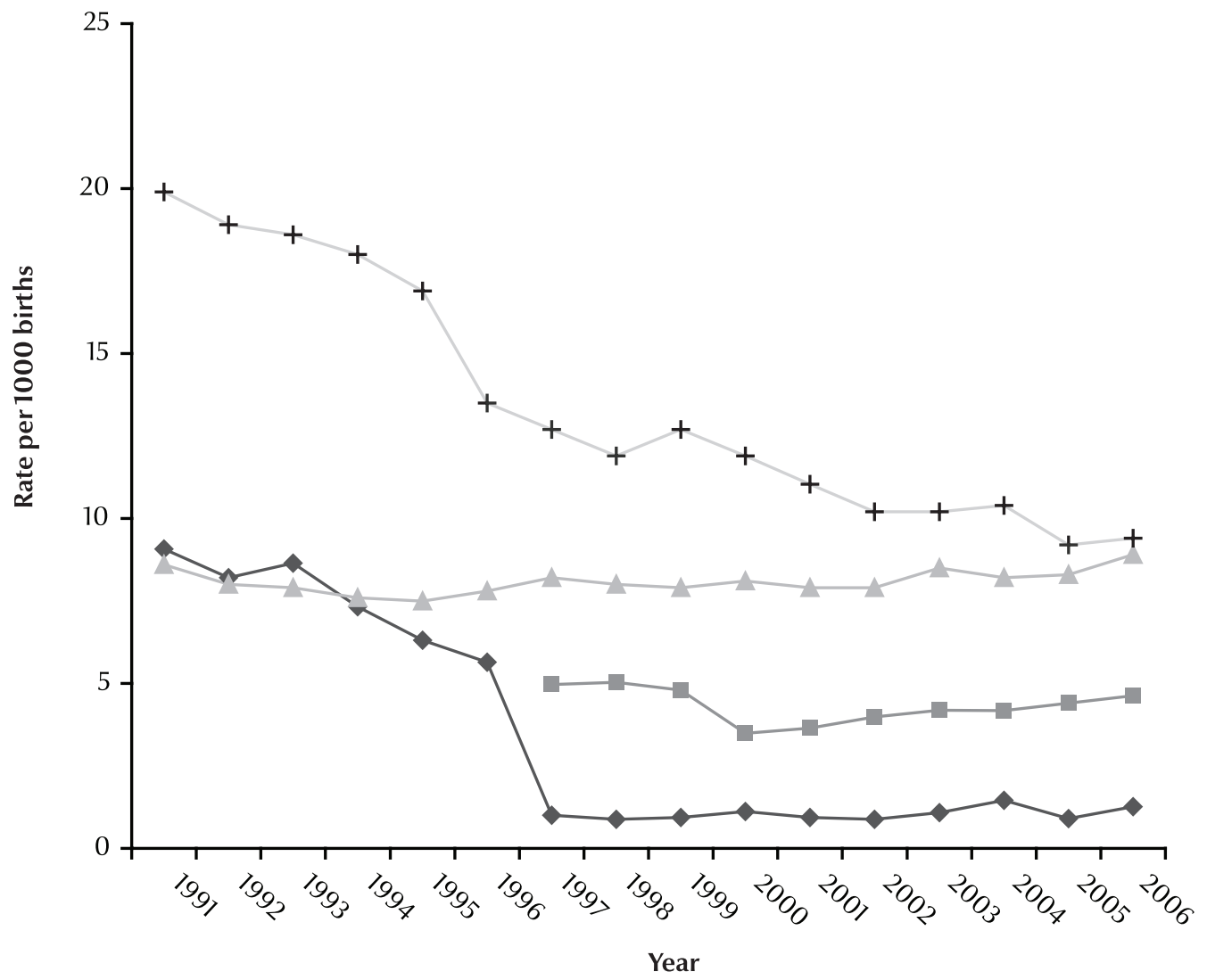

Figure 2 Rates of infant mortality age 0-7 days $(\bullet)$, infant mortality age 7-28 days $(\square)$, low birth weight $(\mathbf{\Delta})$ and spontaneous abortion (+) in Oman health institutions, 1991-2006

consumption of $2100 \mathrm{kcal}$. Figure 3 without flour fortification to $84 \%$ with shows that the contribution of flour and fortification, compared with that from bread to the national per capita folate rice, fruits and vegetables and other consumption would rise from $35 \%$ sources.

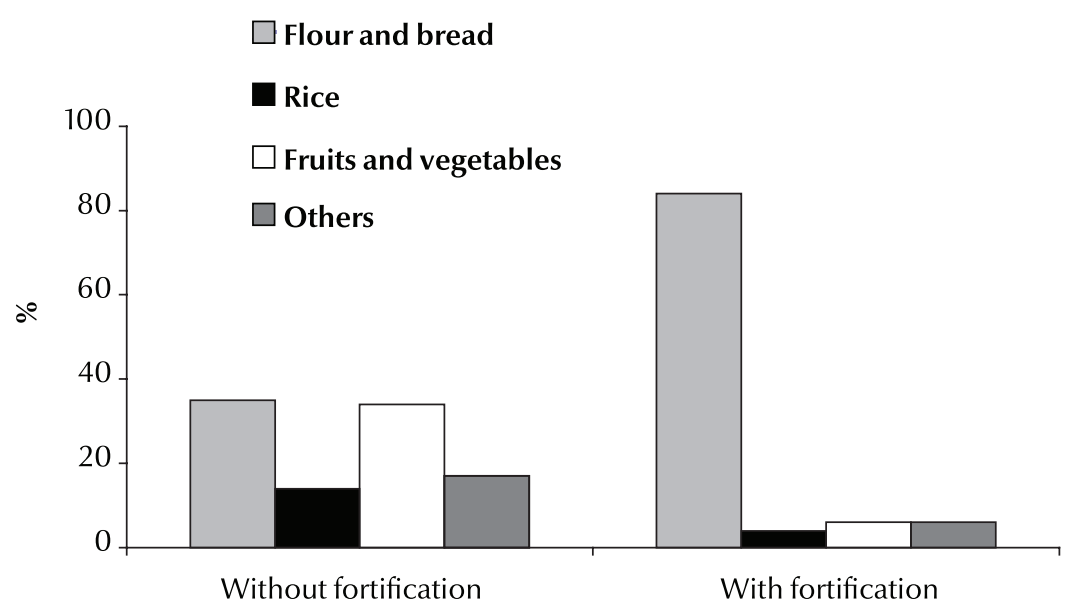

Figure 3 Estimates of percentage contribution of food groups to folate consumption with and without flour fortification based on the average per capita consumption of food items in Oman, 1999 (adapted from the household and income expenditure survey data, Ministry of National Economy, Oman [17])

\section{Discussion}

The rate of spina bifida in Oman in 1996, the year when flour fortification started, was 3.06 cases per 1000 births, which is comparable to the rate in the neighbouring Islamic Republic of Iran where a rate of 2.87 per 1000 was reported in the period 1998-2003 [14]. Starting in 1996, all white flour used in Oman was fortified with iron and folic acid; no other fortificants were mandated. The household coverage of fortified flour and products in 2004 was found to be $81 \%$ [7]. Our data show a sharp decline in the rates of spina bifida in 1997 to 2.11 per 1000 deliveries and in 1998 to 0.78 per 1000 deliveries. The earlier start to the decline in the spina bifida rate from 1995 may be explained by the voluntary initiation of flour fortification in June 1995 before legislation was passed (personal communication, Oman Flour Mills). 
The decline in spina bifida rates corresponded to the start of the national flour fortification programme rather than the start of folic acid supplementation for pregnant women in 1990. Through this national supplementation programme all pregnant women received iron and folic acid tablets at the first visit to the health centre. An assessment of the programme in 1993 revealed that $97 \%$ of all pregnant women attending health centres received the supplements and the compliance rate among them was estimated to be $77 \%$ [15]. Our data are consistent with published data from Nova Scotia that showed no impact on open NTD incidents after folate supplementation, whereas a 54\% reduction was reported following food fortification [16].

The decline in the rates of spina bifida, but not the other NTD, that we found in Oman after 1997 suggests that in order to have an impact on spina bifida rates an adequate folate supply should be ensured before initiation of pregnancy. Periconception folate intake has an important impact on the prevention of NTD and this has been shown in clinical trials since 1992 [17]. The recommended levels of fortification should be tailored to the target population, to take into consideration the population intake of the recommended vehicle, the availability of folate from other sources and other public health programmes, especially now that the issue of safe levels of folate supplies is emerging in the literature [18-21].

Congenital anomalies are the leading cause of infant deaths in the USA [22] and were the second leading cause in infants aged 0-28 days in Oman in the year 2005 [9]. Therefore we investigated the rates of neonatal mortality and abortion during the same period, to ensure that the decline in the rates of spina bifida was not a result of selective abortion or neonatal mortality of affected fetuses and neonates. The abortion rate fell by $30 \%$ during the same period, whereas the rates of low birth weight remained fairly constant at 8 per 1000 live births. Infant mortality, however, showed an observable decline that was not parallel to the level of decline in the incidence of spina bifida.

The benefits of folate have been clearly demonstrated in many other countries. The changes in dietary intake and in red blood cell and serum concentrations of folate in response to removing fortified folic acid were investigated in the USA. It was found that after 12 weeks of elimination of fortified foods red blood cell folate had fallen by 111 $\mathrm{nmol} / \mathrm{L}$ [23], indicating that increasing folate consumption increases serum folate status. Although the mechanism of folic acid in the prevention of NTD is not well established, evidence for an association was shown in the USA, Canada and Chile. After fortification, the rate of NTD declined by $31 \%$ in the USA during the period January 1998 to December 1999 [3]. In Canada the prevalence of open NTD fell from 1.13 per 1000 pregnancies beforefortification to 0.58 per 1000 [4]. In Chile consumption of bread fortified with folic acid improved folate status among women of reproductive age and was associated with a reduction in homocysteine levels in the elderly $[24,25]$. In Oman the reduction in spina bifida rates in 1997, the first year after fortification, was $63 \%$ and a downward trend continued over consecutive years, giving a total average decline in the incidence of spina bifida over the period of $61 \%$ compared with the 1997 rate.

Supplementation strategies have cost and logistic implications and require a well planned marketing strategy if they are to be targeted on the prepregnancy period [26]. However, since a considerable proportion of pregnancies may be unplanned this is difficult to achieve in practice; moreover ensuring continuous compliance throughout pregnancy is a challenge to health workers and pregnant women. Food fortification provides a blanket intervention that ensures adequate consumption of folate on a daily basis for women before and during pregnancy, and its costeffectiveness had been demonstrated [27]. The fortification level set in Oman provided the recommended amount of folic acid for the average population at an increase of $366 \mu \mathrm{g}$ per capita per day. This may explain why the outcome was effective, unlike the experience in the USA where the fortification was designed to add only $100 \mu \mathrm{g}$ to the diet, and showed an increase in the intake of $125-132 \mu \mathrm{g} /$ day for pregnant and lactating women resulting in one-third of them not meeting their requirements $[28,29]$.

Folate is a nutrient that is associated not only with prevention of NTD but also with lowering homocysteine levels and improving birth outcomes in general. It is associated with a marginal but statistically significant increase in the first-year survival rate of spina bifida infants [30]. Folic acid has also been associated with a reduction in homocysteine levels in the serum and in improved endothelial function in adults, which could potentially reduce the risk of cardiovascular disease, while in another analysis folic acid supplementation was found to be associated with an $18 \%$ reduction in initial stroke [31-33].

Primary health care services have witnessed remarkable improvements in Oman in the last 20 years, and the improvement in the general nutritional status of the population is well documented [21]; however this alone is not likely to have a major impact on the incidence of NTD. The benefits of folic acid fortification have been demonstrated in countries that enjoy a high coverage of health services and low rates of malnutrition, such as the USA and Canada. Moreover, the fact that the impact was only seen on spina bifida rates indicates that it is unlikely to be a result of improved health services.

Food fortification is a cost-effective and successful strategy for the prevention of NTD and improvement of 
pregnancy outcomes and also has the potential to prevent cardiovascular diseases. Many countries in the world could benefit from mandatory implementation of folate fortification. Continuous monitoring systems should be put in place to understand its impact on birth outcomes, cardiovascular diseases and cancer.

\section{References}

1. Spina bifida: congenital neurological anomalies. In: Merck manual professional 2005 [online] (http://www.merck.com/ mmpe/sec19/ch292/ch292c.html?qt=spina\%20bifida\&alt=sh accessed 3 December 2009).

2. Scholl TO, Johnson WG. Folic acid: influence on the outcome of pregnancy. American journal of clinical nutrition, 2000, 71(Suppl.):1295S-303S.

3. Spina bifida and anencephaly before and after folic acid mandate-United States 1995-1996 and 1999-2000. Morbidity and mortality weekly report, 2004, 53(17):362-5.

4. Ray J et al. Association of neural tube defects and folic acid food fortification in Canada. Lancet, 2002, 360:2047-8.

5. Department of Obstetrics, Department of Child Health and National Health Program. Antenatal care. Muscat, Oman, Ministry of Health, 1990.

6. White flour fortification with iron and folate. Ministerial Decree number 88/97. Muscat, Oman, Ministry of Commerce and Industry, 1997.

7. Ministry of Health of the Sultanate of Oman, United Nations Children's Fund, World Health Organization Regional Office for Eastern Mediterranean. National micronutrient status and fortified food coverage survey, 2004. Muscat, Oman, Ministry of Health, 2006.

8. International statistical classification of diseases and related health problems (ICD-10) 10th revision. Volume 1. Geneva, World Health Organization, 1992.

9. Annual health statistics report. Muscat, Oman, Directorate General of Planning, 2006 (http://www.moh.gov.om, accessed 3 December 2009).

10. Ministry of National Economy. Income and expenditure household survey for 20/5/1999 to 19/05/2000. Part 1. Muscat, Oman, Directorate General for Social Statistics, 2000.

11. Food processor for Windows, version 8.4.0. Salem, Oregon, ESHA Research, 2004.

12. Preparation and use of food-based dietary guidelines. Report of a joint FAO/WHO consultation. Geneva, World Health Organization, 1998 (WHO Technical Report Series, No. 880).

13. Alasfoor DH, Al Rassasi B, Rajab H. National food based dietary guidelines for Oman-a technical report. Muscat, Oman, Department of Nutrition, Ministry of Health, 2007.

14. Golalipour MJ et al. Epidemiology of neural tube defects in northern Iran, 1998-2003. Eastern Mediterranean health journal, 2007, 13(3):560-5.

15. Evaluation of nutritional anemia control program in the Sultanate of Oman. Alexandria, World Health Organization Regional Office for Eastern Mediterranean, 1993 (EM/NUT/113/E/ $\mathrm{R} /$ 03.92).

16. Persad VL et al. Incidence of open neural tube defects in Nova Scotia after folic acid fortification. Canadian Medical Association journal, 2002, 167(3):241-5.

17. Cretzle AE, Dubas I. Prevention of the first occurrence of neural-tube defects by periconceptional vitamin supplementation. New England journal of medicine, 1992, 327:1832-5.
18. Hathcock JN, Shao AE. Application of risk assessment: an update of safe upper limits (UL) of essential and nonessential nutrients. FASEB journal, 2007, 21:A1065.

19. Hathcock JN. Safety limits for nutrients. Journal of nutrition, 1996, 126:2386S-9S.

20. Vitamins and minerals: efficacy and safety. American journal of clinical nutrition, 1997, 66:427-37.

21. National nutrition surveillance. National nutrition surveillance report, 2009. Muscat, Oman, Ministry of Health, 2009.

22. Metropolitan Atlanta Congenital Defects Program, birth defects surveillance programs research, monitoring and evaluation. 2004 Annual report. Atlanta, Georgia, Centers for Disease Control, United States Department of Health and Human Services, 2005.

23. Cuskelly GJ, McNulty H, Scott JM. Fortification with low amounts of folic acid makes a significant difference in folate status in young women: implications for the prevention of neural tube defects. American journal of clinical nutrition, 1999, 70:234-9.

24. Hertrampf $\mathrm{H}$ et al. Consumption of folic acid-fortified bread improves folate status in women of reproductive age in Chile. Journal of nutrition, 2003, 133:3166-9.

25. Hirsch $\mathrm{S}$ et al. The Chilean flour folic acid fortification program reduces serum homocysteine levels and masks vitamin B-12 deficiency in elderly people. Journal of nutrition, 2002, 132:289-91.

26. Sayers GM et al. A survey of knowledge and use of folic acid among women of childbearing age in Dublin. Journal of public health medicine, 1997, 19(3):328-32.

27. Romano PS et al. Folic acid fortification of grain: an economic analysis. American journal of public health, 1995, 85:667-76.

28. Brent RL. Oakley GP. The Food and Drug Administration must require the addition of more folic acid in "enriched" flour and other grains. Pediatrics, 2005, 116:753-5.

29. Kelly L et al. One third of pregnant and lactating women may not be meeting their folate requirements from diet alone based on mandated levels of folic acid fortification. Journal of nutrition, 2006, 136:2820-6.

30. Bol KA, Collins JS, Kirby RS. Survival of infants with neural tube defects in the presence of folic acid fortification. Pediatrics, 2006, 117:803-13.

31. Picciano MF, Tamura T. Folate and human reproduction. American journal of clinical nutrition, 2006, 83:993-1016.

32. De Bree A, Mierlo L, Draijer R. Folic acid improves vascular reactivity in humans: a meta-analysis of randomized controlled trials. American journal of clinical nutrition, 2007, 86:610-7.

33. Wang $X$ et al. Efficacy of folic acid supplementation in stroke prevention: a meta-analysis. Lancet, 2007, 369:1876-82. 